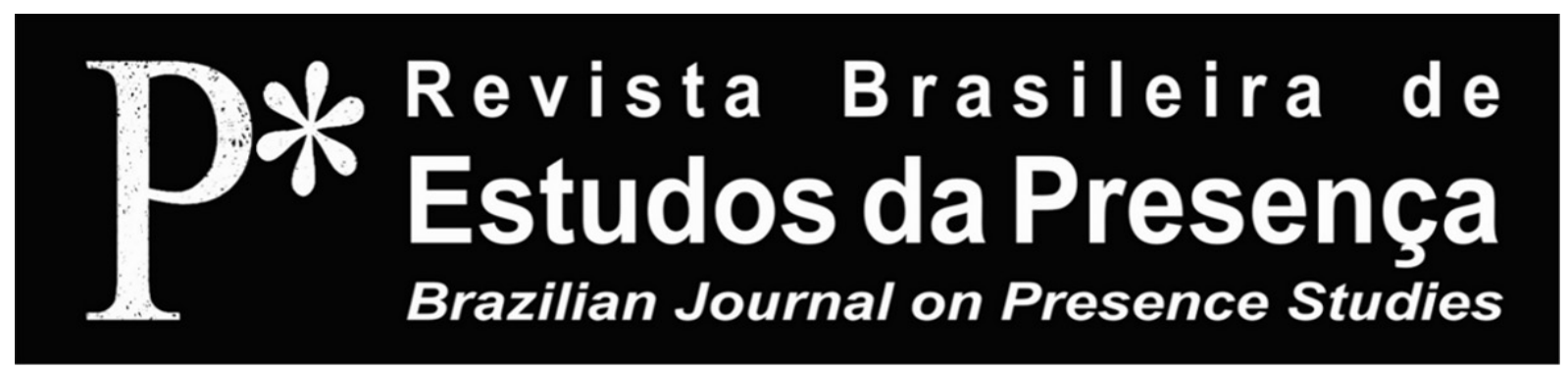

DOI - http://dx.doi.org/10.10.1590/2237-266037894

ISSN 2237-2660

\title{
Corpoestados: singularidades da cognição em dança
}

\author{
Maria Helena Franco de Araujo Bastos \\ Universidade de São Paulo - USP, São Paulo/SP, Brasil
}

RESUMO - Corpoestados: singularidades da cogniçáo em dança - Este texto pretende apontar o modo de produção de conhecimento por meio da dança. Nesse sentido, aborda-se o ato de dançar como modo de elaboraçáo de conceitos, por meios dos quais o artista de dança reinventa o corpo e potencializa sua existência no mundo. No horizonte de análise que se adota, ação e cognição dão-se numa mesma escala temporal, sem distinçôes entre teoria e prática. A proposição do conceito de corpoestados é uma das vias de operação desse modo de conhecer, já que considera as açôes mentais e os atos comportamentais como processos emergentes e comprometidos com os diversos contextos em que estáo inseridos. Palavras-chave: Dança. Corpoestados. Criaçáo. Sujeito. Conhecimento.

ABSTRACT - Corpoestados: singularities of cognition in dance - It is intended in this text to point out the specific mode of knowledge production by means of dance. In this sense, the focus will be the act of dancing as a way of elaborating concepts by which the dance artist reinvents the body and enhances his existence in the world. According to this understanding, action and cognition occur within the same time scale, and thus there is no difference between theory and practice. We propose the concept of 'corpoestados' as one of the ways of operation of this mode of knowledge, since it considers mental actions and behavioral acts as emerging processes, committed to the various contexts in which they are inserted.

Keywords: Dance. Corpoestados. Creation. Subject. Knowledge.

RÉSUMÉ - Corps-états: particularités de la cognition en danse - Cet article se penche sur un mode spécifique de production de connaissance par le biais de la danse. Dans cette perspective, l'acte de danser serait producteur de concepts permettant à l'artiste de réinventer le corps et de potentialiser son existence dans le monde. Laction et la cognition se produiraient donc simultanément, sans qu'il y ait de distinction entre la théorie et la pratique. Pour définir ce mode de connaissance, nous proposons le concept de corps-états qui envisage les actions mentales et les actes comportementaux comme des processus émergents et engagés dans les divers contextes dans lesquels ils sont insérés.

Mots-clés: Dance. Corps-états. Création. Sujet. Connaissance. 
Inicia-se este artigo a partir de um exercício de lembranças pontuadas por memórias, histórias, relatos e afetos capturados pelo corpo, um corpo que dança e percebe o espaço ao se mover. Há nesse mover uma necessidade própria, um movimento que se organiza no desejo de expandir o campo da ação do próprio corpo. Acredita-se que esse é um modo de lidar com o conhecimento, um modo específico das artes na produção de conhecimento. O foco será a dança e o objetivo, apontar que, ao dançarmos, elaboramos conceitos, pois, a cada criação, o artista de dança reinventa o corpo e potencializa sua existência no mundo. Nesse horizonte de análise, ação e cognição dão-se numa mesma escala temporal e sem distinçóes entre teoria e prática.

\section{Sujeitos de Dança entre Potências de Existências}

No início da minha vida acadêmica, as ideias que me eram apresentadas num primeiro instante causavam certo estranhamento, especialmente devido à sua complexidade. Nesses momentos, eu assumia o papel de ouvinte e ficava disponível àquelas informaçóes. $\mathrm{O}$ interessante é que, muitas vezes, acabava elegendo determinadas linhas de pensamento porque, em suas explanaçóes, os professores, mesmo sem querer, deixavam escapar suas paixóes, suas críticas e mençôes aos desafetos. Nessas circunstâncias, algo diferente acontecia em minha percepção. Se alguém pedisse explicações sobre as teorias apresentadas, sem dúvida, eu teria dificuldades de precisá-las. Em contrapartida, quando ensaiava, aquelas sensaçóes invadiam meus gestos, os gestos me dirigiam para leituras e as leituras provocavam conversas com colegas e professores. De alguma forma, eu captava, em movimento, as ideias apresentadas na universidade. Percebi que era me movendo que eu produzia conhecimento. Entre ensaios e aulas, produzia conceitos a partir do meu mover em dança.

Através do tempo, entendi que esse era meu jeito específico de lidar com o aprendizado. Apesar de se constituir como jeito particular, ele não está isolado, mas se conecta com o modo de lidar com o conhecimento da maioria dos artistas quando se lançam numa criação. Quando se debruça sobre uma nova invençáo, todo artista potencializa um modo particular de estar no mundo. Essa organização constrói-se no tempo. Hoje reconhecemos que somos sujeitos diferentes, com formas de sociabilidade que ainda náo havíamos praticado, e essa percepção surge a partir das circunstâncias específicas do mundo contemporâneo. Elas nos apontam transformaçôes 
importantes, relativas ao pensamento de sujeito enquanto construçáo contínua e codependente do ambiente em que se insere e vice-versa. Sempre se é sujeito de algo. Nesse momento, o algo que nos produz como novos sujeitos é o fato de haver muitas instâncias, em diferentes níveis de complexidade, que estabelecem temporalidades distintas no corpo e no ambiente com que se conecta. Negociaçóes impóemse nesse corpo por estar continuamente escorrendo entre diferentes instâncias e produzindo situaçôes que merecem nossa atenção. Existem mudanças substantivas, que nos tornam sujeitos diferentes dos que fomos. Usamos palavras conhecidas de outras maneiras. Elas se transformaram em relação a seus contextos. Lembremo-nos do ato da escrita. Se antes o gesto estava alinhado entre papel e caneta, agora é mediado pelas teclas do computador. Em momentos anteriores, nossos dedos teclavam os aparelhos celulares, enquanto agora deslizam sobre novos modelos. O desamparo torna-se evidente nesse ambiente fluido, em constante mudança, numa velocidade que interfere em nossa apreensão em relação a permanências. Se, no momento, esse vem sendo nosso modo de existir, a arte que daí surge é vulnerável a tais alteraçóes.

Nesse contexto contemporâneo, não somos mais cognitivamente os mesmos e nossas capacidades adaptativas apontam mudanças na comunicação, na ética, na política e na cultura. Evidentemente, a arte faz parte desse conjunto de transformaçóes em curso. Cabe, portanto, pensar quais são os tipos de dança desse outro sujeito que agora somos e produzimos. E tentar discorrer sobre a especificidade da produção de conhecimento em dança e, consequentemente, sua contribuição nesse contexto. Lembremo-nos do filósofo Giorgio Agamben, que propóe o verdadeiramente contemporâneo como aquele que não coincide perfeitamente com seu tempo ou que não está adequado às suas pretensóes. Um artista pode desprezar seu tempo, porém entende que pertence a ele de modo irrevogável.

A contemporaneidade, portanto, é uma singular relação com o próprio tempo, que adere a este e, ao mesmo tempo, dele tomas distâncias; mais precisamente, essa é a relação com o tempo que a este adere através de uma dissociação e um anacronismo. Aqueles que coincidem muito plenamente com a época, que em todos os aspectos a esta aderem perfeitamente, não são contemporâneos porque, exatamente por isso, não conseguem vê-la, não podem manter fixo o olhar sobre ela (Agamben, 2009, p. 59). 
Retomando o início deste texto, é nas próprias criaçóes que o artista pode contribuir e devolver para a academia a especificidade desse conhecimento. São movimentos gerados entre ideias/açóes. É o próprio movimento e o propósito colocado na experiência que nos devolverá o entendimento do que se está produzindo. Realidades despontam na conexáo de um entendimento de mundo e nas escolhas de como se faz discurso. É uma construção contínua. Por isso a ideia de produto e processo se dá de forma conjunta. A cada novo discurso, é uma outra experiência que se compartilha e um modo alterno de se abordar o novo sujeito.

De alguma forma, toda arte faz da experimentação uma possibilidade concreta de manipulação de um problema a ser averiguado. Nesse caso, a experimentação é a elaboração e a criação de caminhos que ajudam a elucidar dúvidas sobre o que se deseja conhecer ou averiguar. A experimentação não contempla apenas uma observação fiel dos fatos tais como se apresentam, nem uma única busca de conexôes empíricas entre fenômenos. Exige, ao contrário, uma interação da abordagem teórica e da manipulação prática, o que implica uma estratégia contundente. $\mathrm{Na}$ verdade, é um processo criativo que se estabelece como chave possível de uma hipótese teórica, e é nessa qualidade que é preparado, antes de se interrogar por meio da teoria. Assim, temos um empreendimento sistemático que volta a provocar a natureza.

$\mathrm{Na}$ interação entre determinada ideia, sua manipulação prática e o mundo em que vivemos, a ação artística incorpora outros conhecimentos. Nessa ação, o empreendimento deve ser sistematizado, ou seja, constituído de diferentes relaçóes de conceitos reunidos a partir de uma realidade que se constitui nas conexóes entre diferentes conhecimentos. Aqui, falamos de dança. Podemos afirmar que essa realidade é sistêmica, isto é, opera como um sistema de ideias que garante sua integridade, sua autonomia e sua perpetuação. Uma vez que o ambiente, enquanto organização de um sistema de ideias, mantém-se, a teoria sobrevive. Ele existe enquanto cria diálogos articulados entre regras de um jogo crítico, a fim de mostrar capacidade de adaptação e transformação nas interaçôes entre os acontecimentos que aí se manifestam. 


\section{( \\ Estudos da Presenca

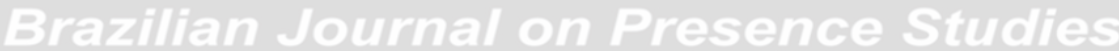

\section{Movimento de Dança: aprendizagem de um olhar}

A dança acontece num ambiente especializado: o corpo - como aquele que aprende a partir de movimentos. Mas o que é que nos dá o entendimento de que o que observamos no espaço são movimentos de dança? Quem observa o corpo percebe que nele ocorrem tanto os aprimoramentos quanto os saltos evolutivos. Qualquer pessoa que tenha experimentado praticar tecnicamente com o corpo - seja dançando, pulando corda, andando de bicicleta, jogando bola etc. - já sentiu as duas formas de ocorrência. A habilidade que se treina melhora gradualmente através de exercício que burila os erros.

$\mathrm{O}$ movimento cria o encadeamento das ideias de uma fala. $\mathrm{O}$ que é entendido como preciso fora do corpo ganha nele outras especificaçóes. Caso o movimento se faça funcionar num rastro de dança, passará a fazer parte de um contexto. O movimento faz o contexto e, ao mesmo tempo, dele depende. Complementando: dança pode ser compreendida como um ambiente construído das diferentes relaçóes e percepçóes de processos. O corpo é o meio desse ambiente que aprende a gerenciar e articular entre diversas informaçóes, replicando determinados padróes de movimentos ou inventando outros padróes de movimento no espaço. Seguindo esse raciocínio, podemos afirmar que dança propicia criação de novos padróes. O neurologista Howard Gardner aponta num extremo:

Diz-se que assim como o mestre bailarino Balanchine forjou o vínculo entre a dança e a narrativa, o coreógrafo contemporâneo da dança moderna Merce Cunningham cortou o nó entre a música e a dança. Cunningham, de fato está interessado no movimento puro e simples; ele gosta de observar insetos em microscópios e animais em zoológicos. Ele é um dos principais formalistas da dança, um inveterado investigador de como o peso e a força interagem com o tempo e o espaço, um paladino da ideia de que a dança é uma arte independente que não requer qualquer apoio a música, nenhum fundo visual e nenhum enredo. Suas danças, portanto, fornecem uma oportunidade para que observemos a inteligência corporal em sua forma mais pura, não contaminada com a sobrecarga representativa (Gardner, 1994, p. 173).

Gardner fala de inteligência corporal e explica que uma grande parte da atividade motora apresenta interaçóes sutis entre o sistema perceptual e o motor. Este apresenta um funcionamento extremamente complexo que exige uma coordenação de uma grande variedade entre componentes neurais e musculares de uma forma diversificada e cooperada. 
Os diferentes meios e contextos de uma sociedade podem ser compreendidos como a cultura que reúne diversos saberes que são transmitidos entre aqueles que ali convivem num determinado momento. Todo sujeito começa a receber a herança cultural, que assegura a sua formação, a sua orientação, o seu desenvolvimento de ser social desde seu nascimento. A herança cultural não vem unicamente se sobrepor à hereditariedade genética, articula-se com esta. Dessa maneira, cada cultura, por meio dos seus escritos, das suas escolas, dos seus medos, das suas práticas alimentares, dos seus valores, dos seus consumos e das suas escolhas de padróes de comportamento entre grupos e individualmente, acaba construindo e transmitindo a qualquer sociedade um capital técnico e cognitivo de saberes.

Desse modo, uma alternativa é entender cultura também como um ambiente do corpo. Um corpo é sempre diverso, múltiplo e poroso em relação aos ambientes em que ele se encontra. Sabemos que o corpo está sempre cruzado por tempos simultâneos e diferentes.

Entendemos que diferentes padrôes coexistem no corpo, um corpo que acontece em movimentos. Cabe a nós aprendermos com esse corpo que dança nas suas diversas instâncias e no ambiente que lhe couber. Nesse sentido, nossa tarefa é tornarmo-nos inventores de experimentos para descobrir de que somos feitos e como somos construídos. Precisamos manter vivo um plano de construçáo para nos tornarmos autores do nosso corpo que dança. Conhecer é construir. Em dança, esse conhecimento se dá com o movimento no espaço, isto é, caminhos no corpo enquanto matrizes cinéticas que se fundem no próprio corpo em que todas as açóes estão movidas por um propósito. $\mathrm{Na}$ maneira de se criar uma dança, o coreógrafo cria uma lógica particular na composição de uma série de movimentos. No tempo, essa lógica pode detectar um novo padrão. Em tempo, essa lógica transforma-se em rastros. Rastros de corpos, pedaços de ideias, enfim, misturas que podem levar a uma nova dança. Cada corpo que dança possui rastros de muitas danças. Sáo conquistas de momentos, espaços entre singularidades que dançam.

\section{Corpoestados: processos emergentes entre fronteiras borradas}

Corpoestados é um conceito proposto para refletirmos sobre a ideia de corpo e do ambiente que se delineia na construção cênica conectada em dança. O corpo é entendido, aqui, como um tipo de 
organização que processa diferentes informaçóes. Outro ponto a ser levado em conta é que qualquer corpo ocupa um espaço numa determinada temporalidade. Esse corpo no tempo aprende a negociar, em diferentes instâncias, no ambiente que lhe couber. A essa altura, podemos perceber que existe um corpo para cada pessoa que conhecemos. A esse respeito, o neurologista António Damásio examina os planos de um processo de construção e desconstrução ininterrupto para se chegar ao que chamamos de personalidade:

Quando descobrimos de que somos feitos e como somos construídos, vislumbramos um processo incessante de construção e demolição, e percebemos que a vida está à mercê desse processo ininterrupto. Como os castelos de areia que construíamos quando crianças, ele pode desmoronar. É espantoso que contemos com um sentido do self, que tenhamos - a maioria, ou alguns de nós - uma continuidade de estrutura e função que constitui a identidade, algumas características estáveis de comportamento que denominamos personalidade. É verdadeiramente espantoso, que seja eu e que você seja você (Damásio, 2000, p. 189).

Podemos perceber uma vulnerabilidade do corpo em sua relação com o ambiente em que se percebe envolvido, já que existe sempre uma interação do corpo com o que está dentro e fora dele. Nesse sentido, o melhor termo a ser empregado para dar conta dessa interação entre corpo e ambiente é contaminação. Uma vez que os processos de contaminação com o mundo são coevolutivos, corpo e ambiente não apresentam uma relação causal unilateral. A contaminação é um processo de mão dupla.

Concordamos com Christine Greiner e Helena Katz quando entendem o corpo como um contínuo entre mental, neuronal, carnal e ambiental. Ambas alertam sobre a impossibilidade de se pensar em corpo sem ambiente, pelo fato de ambos serem desenvolvidos em codependência. $\mathrm{O}$ corpo é produto de acordos entre diferentes informaçóes do ambiente e transfere seu jeito de acontecer para outras instâncias de seu funcionamento. Ou seja, a ação criativa de um corpo no mundo recria os modos que o produziram, como uma onda que chega e parte, qualificada por favorecer e quebrar contatos. Retomando:

Os processos de troca de informação entre corpo e ambiente atuam, por exemplo, na aquisição de vocabulário e no estabelecimento das redes de conexão. Há algumas evidências em teoria de sistemas dinâmicos de que o ato 
de aprender um movimento implica em acoplamento entre sistemas de referência que vão mudando gradualmente de moldura (Greiner; Katz, 2002, p. 94-95).

Cada corpo, de seu jeito, abriga uma maneira de pensar, organizar e relacionar-se com o mundo que, no decorrer do tempo e de acordo com as experiências que sofre, vai modificando e especializando esse próprio corpo. Novos acordos vão sendo estabelecidos a partir da experiência, tanto do ambiente do corpo para o ambiente em que o corpo está envolvido como vice-versa.

Quando afirmamos que o conhecimento produz outros mundos, é pelo fato de ação provocar um conjunto de atividades no corpo de forma cooperada. Sáo acordos e regras criados para interagir com o mundo em que vivemos. Em outras palavras, criamos, no corpo, disponibilidades para a ação cooperada. Dessa forma, podemos afirmar que a lembrança de determinado objeto, que cada um de nós observa em seu corpo, não corresponde a réplicas, mas a interaçóes entre o que foi possível mobilizar no organismo em relação ao objeto e deste em relação ao organismo. A cada relação, são realizados novos acordos, que se transformam pelo aprendizado. O próprio viver habilita o organismo a estar sempre aprendendo. Nosso corpo nunca é o mesmo, pois está sempre em transformação.

Em 1999, George Lakoff e Mark Jonhson, pesquisadores das ciências cognitivas, vão propor a ideia de "embodiment", ou seja, mente corporificada ou encarnada, mente processada a partir de nossas experiências corporais. A compreensão de mente encarnada facilita $o$ reconhecimento de que as complexas relaçóes que envolvem mente, corpo e ambiente contemplam variados níveis. Desse modo, o corpo biológico não é $a$, mas uma das possibilidades de compreensão do corpo.

\begin{abstract}
Nossos ambientes não são apenas físicos e sociais. São também constituídos de artefatos culturais, práticas, instituições, rituais e modos de interação que transcendem e modelam qualquer corpo particular e qualquer particular ação corporal. Estas dimensôes culturais incluem gênero, raça, classe (status socioeconômico), valores estéticos, e vários modos de postura corporal e movimento (Johnson, 2007, p. 202, tradução da autora $)^{1}$.
\end{abstract}

Algumas de nossas capacidades corporais advêm da seleção evolutiva e outras ligam-se às maneiras como nos adaptamos e interagimos socialmente. Temos, portanto, um corpo que também é social. 
Se pensarmos no corpo como um organismo em interação com o ambiente e entendermos que nosso corpo evolui com esse ambiente, estamos no nível que Mark Johnson chama de corpo ecológico (2007, p. 277). Johnson expóe cinco níveis de descrição do corpo - corpo biológico, corpo fenomenológico, corpo social e corpo ecológico. $\mathrm{O}$ quinto é o corpo cultural, que colabora para ultrapassar a tentativa simplificada de atribuir significaçóes fixas ao corpo.

Finalmente, Corpoestados é proposto aqui como conceito por entendermos que o corpo é, ao mesmo tempo, biológico e cultural, tanto quanto é social, fenomenológico e ecológico. Essas terminologias nos ajudam a descrever o fenômeno, mas, de fato, não há como separar as várias dimensóes que nos facultam compreender o corpo, pois os níveis diferentes de descrição estão inteiramente entrelaçados, do biológico ao cultural. Ao nos expressarmos, nossos gestos e nossas falas estão juntos, conectados e interligados ao fluxo do pensamento e das emoçóes. E essas açóes sáo potencializadas quando o artista se debruça sobre uma criação. Nessa conexão, o corpo não pode ser compreendido como um produto pronto, pois muda de estado a cada vez que acontece uma ação, quer dizer, as variaçôes que invadem nossa percepção no instante em que o corpo precisa criar soluçóes no espaço. Nesse estado de moveres, as soluçóes encontradas nos levam a descobrir outras possibilidades de organizar o corpo no espaço, já que não há separação entre mente e corpo. Desse modo, um pensamento prático-teórico é elaborado.

Dança, neste contexto, é entendida como um ambiente que interage com diferentes questóes provocadas por necessidades que o corpo cria em relação a si mesmo. O corpo pode criar, coreograficamente, a partir de instruçóes. Quando invadem o corpo, essas instruçóes sofrem variaçôes que dependem da coerência estabelecida entre o momento de uma determinada açáo, o modo como provocamos essa ação no corpo e nossa percepção do espaço que está no entorno da ação. Na relaçáo com a criação, é como se, a cada escolha, o corpo produzisse um trânsito entre instantes e permanências, com diferentes graus de sucessos e insucessos. Sáo muitas vozes que reverberam de modo simultâneo e com níveis de complexidades distintas na criação de uma dança. No pensamento contemporâneo, essas convivências tornam-se mais expostas. 


\section{Nota}

${ }^{1}$ No original em inglês: "Our environments are not only physical and social. They are constituted also by cultural artifacts, practices, institutions, rituals, and modes of interaction that transcend and shape my particular body and any particular bodily action. These cultural dimensions include gender, race, class (socioeconomic status), aesthetic values, and various modes of bodily posture and movement" (Johnson. 2007, p. 202).

\section{Referências}

AGAMBEM, Giorgio. O que é o Contemporâneo? E outros ensaios. Tradução: Vinícius Nicastro Honesko. Chapecó: Argos, 2009.

DAMÁSIO, António. O Mistério da Consciência: do corpo e das emoçôes ao conhecimento de si. Tradução: Laura Teixeira Motta. Revisão técnica: Luiz Henrique Martins Castro. São Paulo: Companhia das Letras, 2000.

GARDNER, Howard. Arte, Mente e Cérebro. Tradução: Sandra Costa. Porto Alegre: Artes Médicas Sul, 1999.

GREINER, Christine. O Corpo: pistas para estudos indisciplinares. Sáo Paulo: Annablume, 2004.

JOHNSON, Mark. The Meaning of the Body. Chicago: University of Chicago Press, 2007.

JUARRERO, Alicia. Dynamics in Action: intentional behavior as a complex system. Massachusetts: MIT Press, 1999.

KATZ, Helena. A Dança é o Pensamento do Corpo. Belo Horizonte: FID Editorial, 2005.

LAKOFF, George; JOHNSON, Mark. Philosophy in the Flesh: the embodied mind and its challenge to western thought. New York: Basic Books, 1999.

THELEN, Esther; SMITH, Linda. A Dynamic Systems Approach to Development: applications. Massachusetts: MIT Press/Bradford Books Series Cognitive Psychology, 1994.

Maria Helena Franco de Araujo Bastos, de nome artístico Helena Bastos, é coreógrafa e bailarina. Doutora em Comunicação e Semiótica pela Pontifícia Universidade Católica de São Paulo (PUC-SP). Atualmente, é professora de Dança Contemporânea e chefe do Departamento de Artes Cênicas (CAC) da Escola de Comunicaçôes e Arte (ECA) da Universidade de Sáo Paulo (USP) na graduação. Professora credenciada no PPGAC (Programa de Pós-Graduaçâo em Artes Cênicas) cuja linha de pesquisa é "Texto e Cena". Cofundadora e associada da Associação Nacional de Pesquisadores em Dança (ANDA).

E-mail: helenahelbastos@gmail.com 